\title{
FERNANDO ROSENZWEIG
}

Algunas reflexiones en torno de la economía campesina

\section{Presentación}

7 Tengo el gusto de que aquí esté con nosotros el Dr. don Fernando Rosenzweig, que seguramente para muchos de ustedes no necesita presentación. Para los pocos que sí la necesite, el Dr. Rosenzweig es gran conocedor de la hisoria económica de México, ha impartido cursos de Historia económica y ha dirigido seminarios de este tema en diferentes lugares, como El Colegio de México, la UNAM y aquí mismo, en el ITAM. Fue Director del CIDE y también ha sido director y funcionario en diversos organismos paraestatales.

Para introducimos al tema, tódos sabemos que hoy es aniversario de la muerte de Emiliano Zapata. Los que estén más o menos familiarizados con lo que es la vida del campo, podrán pensar que la lluvia, que suele ser para los campesinos el primer signo de esperanza - es en ese momento cuando se empieza a mojar la tierra para poder sembrar- es precisamente el día de hoy para varios cientos o miles de campesinos no tanto signo de esperanza, sino otra molestia más de las varias que han tenido que pasar en la ciudad de México al marchar por las calles para expresar sus exigencias y protestas por la situación en la que viven en el campo.

Zapata es uno de los héroes de la Revolución que ha sido tomado como bandera por grupos que no están completamente asimilados al sistema mexicano y que espontáneamente le hacen un homenaje, además de los homenajes oficiales. Además, es un homenaje con sentido de protesta.

Quizás para nosotros está muy lejano el tema de Zapata y lo que

- Conferencia presentada el 10 de abril de 1987, en la Biblioteca Manuel Gómez Morín, en el ITAM, en el $68^{\circ}$ aniversario de la muerte de Emiliano Zapata. 
implica, pero todavia el sexenio pasado era muy viva la discusión sobre la economía campesina, de la cual era representante o símbolo Zapata, frente a la economía agrícola de tipo comercial. Así como hoy en día los temas de debates públicos son el petróleo, la deuda externa, el GATT, el sexenio pasado lo era mucho la cuestión de la economía campesina y la producción de autosuficiencia, y la economía comercial y la producción agrícola para exportación. De estas discusiones salieron planes públicos, como el SAM (Sistema Alimentario Mexicano) y salió también la Ley de Fomento Agropecuario. Como digo, el asunto estaba en el tapete de las discusiones de cada día. En cambio, en este sexenio, parece un tema olvidado. Sin embargo, si no se menciona mucho no es porque no sea importante, sino quizás porque en sólo unos años se ha hecho mucho más dificil la situación en la que se encuentra la economía campesina.

Entonces, por este motivo le hemos pedido al Dr. Rosenzweig que nos haga una presentación de la historia de las vicisitudes de esta economía campesina que va muy unida a Zapata, desde la época que dio origen al movimiento zapatista hasta nuestros días en que erróneamente pudiera creerse que ya no tiene caso discutirse. Vale la pena pensar qué es lo que implica el desarrollo del país en los últimos años para todo ese sector de la realidad mexicana que el día de hoy se mostró en la ciudad de México de una manera especial. Entonces, voy a ceder la palabra al Dr. Rosenzweig.

(Rafael Landerreche, Director de la Biblioteca Manuel Gómez Morín.)

\begin{abstract}
A gradezco muchísimo la invitación para presentar ante ustedes algunas reflexiones sobre este tema tan importante esta noche. Debo decirles que quizás hubiese yo deseado preparar un texto escrito, un texto más formal para dejárselos aquí, pero no habiendo tenido el tiempo para ello, en un recinto académico como el ITAM donde las ideas deben estarse manejando constantemente, yo me siento alentado a venir y presentarles, aunque sea un tanto informal, mi reflexión sobre el tema tan importante que el Sr. Lic. Rafael Landerreche acaba de referir. Desde luego sí está muy en su punto y es muy de aplaudirse la iniciativa de venir a hacer consideraciones
\end{abstract}


hoy en relación con la economía campesina en el aniversario de la muerte de Zapata. Si alguien encarna precisamente la idea de una economía campesina que no solamente hubiese significado una resolución económicamente viable - que en esto no hay duda - para el campesinado es Emiliano Zapata, quien tenía sobre todo la preocupación de una redención humana, objetivo válido y no logrado por el que hemos de seguir luchando. Entre tanto voy a pasar a exponerlo.

El enfoque desde el punto de vista económico tiene no pocos problemas, de una gran seriedad. Primero intentaré una caracterización de los rasgos más importantes, sobre todo de los ıasgos que es más significativo que nos ocupemos en analizar en este momento para entender la economía campesina y para ver qué proyección podría tener, dentro del cuadro actual, la situación social económica y política del país.

Podríamos convenir brevemente en que la economía campesina se expresa fundamentalmente en unidades productoras que se orientan fundamentalmente hacia el abasto del consumo familiar. La finalidad esencial del productor campesino es abastecer su propia economía doméstica, en este sentido se habla de economía de autoconsumo o de economía orientada hacia el consumo, en la que no solamente se producen, o no necesariamente en forma exclusiva, productos agrícolas sino que el productor campesino normalmente completa su actividad económica o práctica paralelamente a la actividad agrícola con una actividad artesanal. De tal manera que entre la actividad agrícola y la actividad artesanal realizadas por la familia no sólo se satisfaga el consumo familiar, sino que se pueda obtener un excedente para intercambiarlo en el mercado y obtener otros satisfactores que la familia necesite, y a veces el pago de los impuestos que exige el Estado. Entonces, lo que hay que subrayar es la orientación de la unidad productora hacia las necesidades de la familia, la preocupación por obtener bienes directamente consumibles por la familia y luego, complementariamente, la generación de un excedente de productos artesanales y de productos agrícolas que llevará al mercado con los cuales podrá completar el consumo de la familia, cambiarlos por dinero y con ese dinero obtener aquellos otros bienes que la familia no produce directamente.

Se trata de una explotación de tamaño pequeño, es decir es la explotación que puede funcionar con la aplicación del trabajo per- 
sonal del propietario más los brazos familiares y quizás, en algunos momentos para algunas tareas que requieran la máxima aplicación de mano de obra, con cierta forma de cooperación entre las familias, entre los vecinos. Pero la escala es pequeña y está relacionada fundamentalmente con aquella cantidad de trabajo de que dispone la familia y que puede absorber un predio, como digo, normalmente en pequeña escala. Podemos decir que históricamente la economía campesina característica ha ido perdiendo terreno, ha ido disolviéndose a medida que los procesos de desarrollo, los procesos de integración de economías ya en fase industrial van implicando la transformación de la producción del campo totalmente en una producción de carácter mercantil, es decir, la transformación total de la actividad en el campo en una actividad orientada hacia el mercado y que se realiza por empresas. Ante esas empresas va disolviéndose la economía campesina.

Cuando la producción del campo queda confiada a esas empresas de carácter comercial, a la población del campo le suceden dos cosas; parte de ella se transforma en asalariada de las empresas agrícolas modernas y otra parte emigra del campo hacia otras actividades, hacia la ocupación urbana.

Comparativamente, podemos analizar casos de países en el momento en que han entrado en fases de desarrollo industrial, como Inglaterra donde se trata de disolver estas formas de producción precapitalistas, para que la economía desemboque totalmente en el advendimiento del capitalismo.

Lo que nos ha ocurrido en México, haciendo una presentación muy sintética, muy esquemática del problema, es que jamás el desarrollo de la producción mercantil ha sido de tal intensidad que haya absorbido totalmente a la economía campesina.

A lo largo de nuestra historia, si bien me voy a detener de la Revolución para acá, quiero nada más mencionarles que en aquellas etapas en que ha habido desarrollo de la producción para el mercado ha habido obviamente un retroceso de las formas de la economía campesina. Un momento muy importante se da a comienzos del siglo XVII, después de la Conquista, primer siglo en donde comienza a desarrollarse la hacienda.

La hacienda comienza a convertir la parte de la población del campo en peones para que trabajen la hacienda. Las tierras van pasando de propiedad de las comunidades campesinas a propiedad 
de las haciendas, pero este proceso se detiene en un momento en el cual la hacienda o la empresa orientada hacia el mercado de propiedad privada, la actividad mercantil en el campo, deja de expandirse, en el momento en que ha logrado satisfacer la demanda que tiene delante de sí. En aquel momento en que ha podido absorber toda la tierra y todos los brazos que se requiere para alcanzar ese nivel de producción se detiene la expansión de la propiedad privada y de la empresa mercantil en detrimento de la economía campesina.

Así sucede durante el comienzo de este proceso después de la conquista, así sucede en la etapa de auge de la economía novohispana anterior a la Independencia durante la segunda mitad del siglo XVIII, en que hay un gran auge económico, una expansión de la propiedad privada para la respuesta a la demanda de los productos agrícolas creada por el auge de la minería, por el desarrollo de las ciudades coloniales, etc.

También llega un momento en que las haciendas que están en expansión, están absorbiendo tantos terrenos como brazos de las comunidades campesinas, este proceso se detiene en el punto en el que lo requiere la satisfacción de la demanda en el mercado; entonces subsiste la economía campesina, la unidad campesina al lado de la propiedad privada. Antes de la Revolución, en la última gran etapa en donde este proceso se da, es durante el Porfiriato.

Entre la consumación de la Independencia y el Porfiriato está un período de inestabilidad, en que la economía crece poco, más bien hay un estancamiento en la actividad económica en donde el crecimiento dinámico de los mercados se detiene y donde incluso parte de la población que ya había entrado al peonaje, que ya se había incorporado a la vida de las haciendas o que ya estaba pasando a la ocupación no-agrícola se revierte hacia la agricultura y son todos esos años del siglo XIX, durante el Porfiriato incluso, una etapa en la que se reafirma la comunidad campesina. Otra vez se desarrolla esa forma de producción con las características que decía yo al principio de esta discusión.

Durante el Porfiriato ocurre este proceso que les acabo de decir a ustedes, incluso hay disposiciones legales por medio de las cuales se busca el objetivo de disolver la comunidad campesina e incorporarla a la economía capitalista en expansión. Entonces se promulga la ley de desamortización de bienes de manos muertas, que se aplica primero a los bienes de la Iglesia e inmediatamente también a todas 
las tierras propiedad de las comunidades indígenas, que van a ser fraccionadas y reducidas a propiedad privada. Si bien por la entrega de un título se va a dar legalmente una preferencia a los miembros de las propias comunidades campesinas para que ellos sean los primeros en convertirse en propietarios privados, la realidad es que este objetivo de la ley no se logró y que fundamentalmente las tierras de las comunidades campesinas pasaron a ser parte de haciendas.

Entonces hay de nuevo un proceso de retroceso de la comunidad campesina que no ocurre de manera uniforme en todo el país ni ocurre en todo el país - en México siempre tenemos que acostumbrarnos en buscar los matices que todos los menores tienen de región a región. Fundamentalmente ocurre en las áreas que quedan articuladas por los sistemas modernos de comunicación, es decir donde las tierras agrícolas quedan servidas por líneas de transporte que permiten explotar los productos en escala comercial y en donde se puede desarrollar su producción en escala comercial. En cambio, en aquellas áreas del país más aisladas, fuera de estas grandes líneas de comunicación la comunidad campesina persiste. Ahí donde la nueva economía en expansión no le disputa los recursos a la comunidad campesina, no atrae la mano de obra hacia las haciendas.

Como ustedes recuerdan, el planteamiento de la Revolución Mexicana en materia agraria comenzó precisamente por la reivindicación de Zapata, el Plan de Ayala. Con su lema "Tierra y libertad", Zapata comienza siendo una bandera de reivindicación agraria con el objeto de recuperar los terrenos de los que las comunidades campesinas habían sido desposeídas durante el Porfiriato.

Entonces el proceso de reforma agraria comienza siendo el primer planteamiento de un proceso de restitución de las tierras, de restitución de los predios, de restitución de las parcelas de las comunidades campesinas. Entonces la primera ley, expedida por don Luis Cabrera, que es la ley del 6 de enero de 1915, antecedente del artículo 27 constitucional, es en esencia un planteamiento para la restitución de las tierras de que habían sido despojadas las comunidades campesinas.

Finalmente, la primera fórmula que se expresa en el Artículo 27 constitucional y la doctrina que está atrás de este artículo, desarrollada por Andrés Molina Enríquez en su famoso libro Los grandes problemas nacionales, contiene la siguiente filosofía: Debemos de redistribuir la tierra en México de tal manera que los grandes latifun- 
dios queden segregados en propiedades privadas de un tamaño que permita ser explotado con eficiencia, utilizados intensivamente los recursos por parte de propietarios privados. Entonces se tiene mucho el modelo del pequeño propietario francés, que está muy presente en todo el pensamiento, incluso es parte de la tendencia positivista y de la cultura liberal que se recibe en México con el siglo XIX. Ese modelo de explotación se traslada a nuestro país, empresario individual que tiene una propiedad de tamaño media, que la explota en escala comercial, que es un eficiente abastecedor del mercado, que está dando ocupación a la mano de obra campesina que tiene a su disposición. Esta es la fórmula número uno que expira la legislación del Artículo 27 constitucional; en la fórmula número dos la idea fundamental es la persistencia de la comunidad campesina - a la que estamos restituyendo la tierra - al lado de la propiedad privada. Estos son los dos pivotes alrededor de los cuales va a girar la economía agrícola del país y la vida del campo mexicano, la vida del campesinado del país.

Con el andar del tiempo, cuando las agitaciones agrarias finalmente culminan con la aplicación de la Reforma Agraria del período del Sr. Cárdenas, 1934-1940, el concepto de restitución a la comunidad campesina que había sido desposeída en favor del propietario privado, se amplía, se habla ahora no sólo de restituir sino de dotar de tierra a quienes nunca la habían tenido. Entonces ya se habla de acciones de dotación aparte de acciones de restitución, entonces ya se habla de otra serie de núcleos de población, distintos de las antiguas comunidades campesinas, con los cuales se adquiere el compromiso de dotarles la tierra en virtud del nuevo código agrario, de todas las disposicines que se dan en la materia y que se van aplicando en la Reforma. Cuando el General Cárdenas analiza las orientaciones y los resultados de la política agraria dice, tenemos estas dos formas, las dos tienen que coexistir y entre las dos tienen que darnos una agricultura eficiente y un bienestar en el campo. Entonces la fórmula finalmente queda establecida en la Constitución y es la que inspira a la actual zona agraria. Ahora bien, ésta ha sido le ley, lo cual no ha sido la realidad en la que se ha vivido en el campo, en realidad han ocurrido varios fenómenos. Primero, aunque está por demás decirlo, señalémoslo explícitamente, no hemos tenido un sistema económico de tal dinamismo que haya generado toda la demanda de fuerza de trabajo fuera de la agricultura, capaz de hacer 
emigrar del campo hacia las ciudades a toda la población. Nos ha faltado una demanda de brazos como la que ocurrió en los países capitalistas más avanzados, donde esta demanda generada por el desarrollo dinámico de la economía industrial y de los servicios, generó una demanda de brazos que ha operado todo ese proceso de transformaciones de la economía campesina en la economía mercantil y la incorporación de la fuerza de trabajo a nuevas áreas. La forma en que ha evolucionado nuestra economía ha determinado que no haya demanda suficiente para que se traslade una parte importante de la población rural, que ha permanecido dentro de la forma de la economía campesina, digamos como primer elemento.

El segundo elemento es que en esta igualdad que hemos creado, el sistema de la propiedad privada se ha apropiado del sistema de economía campesina. Constantemente la economía campesina ha ido perdiendo terreno frente a la economía privada, esta cosa ha sucedido en distintas formas.

En primer lugar, la economía campesina se encuentra en una posición desventajosa en la competencia por los recursos naturales, entonces generalmente a los productores campesinos les van tocando las tierras de menor calidad. Generalmente también en el reparto de los recursos hidráulicos, de los ríos y las aguas les toca una menor parte, o sea se encuentran en una posición desventajosa, es una posición de retroceso de la pequeña propiedad. Lo mismo va ocurriendo por lo que se refiere a los recursos económicos, es decir el acceso al crédito, el acceso a los mercados, las condiciones en que se realiza el intercambio de los productos en los mercados. $Y$ aun también por lo que se refiere al mercado de trabajo, cuando quienes pertenecen a las comunidades campesinas buscan procurar un excedente para completar su economía familiar realizando ventas de su fuerza de trabajo, también en ese caso se encuentran en desventaja.

Por otro lado, la población del campo incluida en la forma de la economía campesina tiene desventajas para la utilización de tecnologías más avanzadas, algunas de las cuales implican un aumento de la escala de producción, y luego digamos que las tecnologías que van imponiéndose, que han ido desplazando la tracción animal con la tracción mecánica y han ido difundiendo los insumos químicos van forzando la transformación de la economía agrícola en la medida en que muchos de los bienes, muchos de los intrumentos, muchos de los insumos vinculados por la tecnología anterior no se producen ya y 
dejan de ir latièndo digamos, para imponerse la tecnología más avanzada que va marginando a los productores campesinos; van quedando al margen de la posibilidad de aplicar esas tecnologías más avanzadas.

A estos factores se agrega un problema adicional, que es el del que encima de todo, el esquema de desarrollo que se hubo seguido durante largos períodos ha sido desfavorable, es decir hemos tenido precios relativos desfavorables para los productores del campo en general. Por lo que toca a los productores campesinos, es un factor que se agrega a los demás factores desfavorables, que contribuyen a explicar su situación.

Entonces, teniendo posibilidades de absorción campesina limitadas - como ustedes saben la proporción de la población rural ante la población total del país ha crecido - que no ha sido una absorción suficiente, lo que ha funcionado como una válvula de seguridad, que ha funcionado a medias, con muchos problemas, ha sido la demanda de brazos en Estados Unidos. Las dolorosas emigraciones de trabajadores agrícolas a los Estados Unidos, que en núcleos importantes ya se han convertido en emigraciones definitivas de población, como las que tuvo Europa en otras condiciones el siglo pasado, cuando efectivamente había sobrantes de población en el campo europeo que no absorbía el crecimiento y que determinaron fuertes migraciones a Estados Unidos, hacia Nueva Zelandia, Australia, etc.

Entonces dentro de este conjunto de circunstancias llegamos a un cuadro en donde lamentable y dolorosamente nos encontramos ante una marginación de núcleos muy importantes de la población campesina. Porque aparte de todo digamos, ha habido un empobrecimiento de los suelos, una distribución de la tierra por la que han ido reduciéndose los tamaños de las parcelas, un fenómeno de marginación en donde a la pobreza resultante de la situación en la que se encuentra la economía campesina, se asocian los datos de la ignorancia, del analfabetismo, de la falta de protecciones sanitarias, etc.

De tal manera, nos encontramos ante un México totalmente distinto del México que contemplamos cuando, digamos, reducimos nuestra meditación a los problemas nuevos, que ya también son bastante grandes. Entonces tenemos que admitir, digamos, que la estrategia de desarrollo que hemos seguido nos ha conducido a esta 
marginación de la población del campo, para eso están las lecciones de la historia económica para decírnoslo.

La trayectoria del desarrollo de la integración de una economía de mercado implica la superación, la disolución de las formas de la economía campesina, pero al mismo tiempo están, digamos, el problema de la realidad humana de la marginación, del empobrecimiento de las condiciones en que se encuentra este sector tan importante de la población, éste que vive dentro de la economía campesina, como para que simplemente dijéramos, bueno pues, la solución económica es que el proceso siga, no podemos hacer nada al respecto porque no encaja dentro de un concepto de funcionamiento eficiente de una economía de mercados, de una economía que va hacia el intercambio, sino que realmente nos plantea un problema. Si no lo queremos ver en términos económicos -y tenemos la obligación de buscarle su traducción en términos económicostenemos que verlo primero como un problema humano, como un problema social, como un problema político.

No podemos ignorar que una parte de la población del país no encuentra condiciones para hacer una vida satisfactoria, tiene cerrado el camino del bienestar porque está, digamos, incorporada a otra forma de producción, se encuentra en una situación de precariedad que no permite alcanzar un nivel de vida satisfactorio.

De alli proviene toda esta preocupación que ha aparecido en todos los círculos responsables de la sociedad mexicana adoptando muchas formas y con distintos enfoques que buscan soluciones al problema de la economía campesina, con el objeto de poder asegurar un camino de bienestar.

Ahora, si lo vemos desde otro punto de vista, digamos desde el punto de vista de una estrategia de crecimiento en donde estemos considerando que de alguna manera el proceso de desarrollo del país seguiría igual hasta llegarse a una etapa en que tengamos mejor integrada la economía nacional y que dentro de esa mejor integración hayamos ya situado a las comunidades campesinas, una perspectiva nueva en donde incluso las hayamos absorbido por la vía de la generación de empleo, por la vía de un desarrollo más pujante de una economía agrícola moderna, si hasta incluso estamos contemplando eso, tenemos que pensar qué cosa va a pasar con esta economía campesina y con las personas que viven en esta comunidad campesina, durante el proceso de la transición. ¿Las vamos a dejar morir? 
Una fatalidad, tal parece por momentos que es la posición de la sociedad mexicana. No podemos decir, son las fatalidades de nuestra gran población, de nuestro crecimiento demográfico rápido; nuestra economía no da para más y nuestras inversiones no se pueden extender más, sino que tenemos que partir de la base de que esto no debe suceder. Yo creo que de ninguna manera un fatalismo podría ser la posición correcta y creo que la economia y las soluciones que puede proporcionar la economía deben estar subordinadas a un concepto de objetivo social, de necesidades sociales, de problemas humanos, porque al fin y al cabo la economía debe orientarse a problemas humanos.

Entonces, hay una serie de consideraciones que hacer en relación con posibles soluciones, y yo simplemente no hago más que transmitirles a ustedes las inquietudes que yo mismo tengo. Hay muchos factores que condicionan el uso de los recursos sociales dentro de nuestro país y la orientación de nuestra política de gasto tiene muchos problemas y limitaciones. Yo me atrevo, por lo menos, a mencionar como reflexiones algunos puntos que me parecen sumamente importantes.

El primero se refiere a uno de los elementos que mencionaba yo para caracterizar el cuadro, es la ignoracia, el analfabetismo en los más bajos niveles de la población. Yo creo que se ha hablado mucho en nuestro país, y la historia de la educación en México está llena de pronunciamientos, por lo menos desde Vasconcelos para acá, en donde se dice eduquemos y enseñemos el alfabeto y vamos a redimir a la población mexicana. Yo creo que es una esperanza fundamental, pero el sólo conocimiento del alfabeto no resuelve problemas como los que les acabo de mencionar a ustedes.

Es importante que subrayemos el papel de la educación entendida en su verdadero aspecto, es decir como desarrollo de la conciencia de las gentes, es decir una educación orientadora que ayude a las personas, que ayude a la población campesina, que ayude más alrededor de entender en qué situación se encuentra viviendo y porqué se encuentra viviendo en esa situación. No para que junto con esta conciencia que estamos fomentando en ellos nosotros mismos les digamos qué deben hacer, no estamos capacitados para decirle a cada uno, yo tengo la fórmula de lo que a ti te conviene, no sería cierto. Cada una de las personas que están en la población del campo tiene su propia realidad y si nosotros le damos medios de conocimiento va a entender mejor esa realidad, va a encontrar 
caminos para enfrentarse a esa realidad e ir mejorando su situación. Una población con un grado de instrucción se va a enfrentar mejor a los altos problemas que está viviendo en esos momentos dentro de la comunidad campesina. A mí me ha tocado participar en algunos de los programas del sector educativo y sé que no se puede tener la pretensión de que la educación va a resolver todos los problemas, ni el maestro debe de llegar con la pretensión de que tiene la solución para los problemas que la gente está viviendo; la actitud del maestro debe ser ayudar. Hay una acepción de la palabra "escuela" en el idioma de una de nuestras culturas nativas que significa "casa donde se enseña a ver". Creo que la labor educativa es la de abrir los ojos para que las gentes entiendan mejor la realidad en la que viven y dentro de esa realidad sean capaces de distribuir mejor las soluciones a sus problemas.

Hecha esta afirmación hay que señalar algunos aspectos más, digamos, de la promoción humana, como la que se refiere a fomentar la salud entre la población campesina. Digamos en general, se trata de aumentar el esfuerzo para el cuidado de la salud de la población del campo, pero ningún tipo de posible solución debe de hacer perder de vista las posibilidades que puedan encontrarse en dos aspectos fundamentales. Uno sería el de aquellas posibilidades que tiene la población del campo de utilizar más eficientemente los recursos naturales, con lo que habría posibilidades de mejoramiento de la producción campesina. Digamos entonces que, estaríamos buscando devolver un grado de autosuficiencia a la economía campesina, pero con el auxilio de métodos modernos que puedan desarrollarse en el campo de la agronomía, por ejemplo con la cría de animales.

Otra estrategia tiene que ver con la posibilidad de estructurar las unidades campesinas en unidades mayores a través de formas de organización cooperativa, a través de formas de agrupamiento solidario de los productores del campo con los objetivos de lograr mejorar los términos de la comercialización, los términos de abastecimientos de insumos y poder aprovechar mejor los recursos de que dispone.

Son desde luego fórmulas y no se pueden trabajar como fórmulas fáciles de plasmarse y generalizarse, sino que implican un esfuerzo por parte de todos para su aplicación, por eso estamos interesados por este problema, para ir encontrando planteamientos racionales en donde le demos a la población que está viviendo en esta situación un 
papel activo y no un papel pasivo, como mero sujeto receptor de unas acciones o como meros participantes pasivos en las iniciativas que se tomen desde fuera de estas comunidades.

Creo que uno de los problemas más graves que nos han ocurrido en el tratamiento que le hemos dado a la población del campo ha sido, tenerla sometida a la situación que les describía yo al principio, que conduce a la marginación, y al mismo tiempo decirles nosotros cómo salir de la marginación. Cuando, lo que tenemos que hacer es ayudarlos a que entiendan porqué están marginados, cómo están marginados, cómo están viviendo y pongamos todo el conjunto de instrumentos de promoción humana, de promoción económica para ayudar a que la gente salga por sí misma de la situación en la que se encuentra.

Estoy hablando, y esto es lo último que voy a decir, en contra de la vieja política, una vieja práctica en la que hemos incurrido en todo el trabajo del campo mexicano, que consiste en la actitud paternalista: Tú estás en situación inferior, yo vengo a ayudarte, haz todo lo que yo te voy a decir. Ese paternalismo es el que tenemos que romper, pero digamos, no adoptando una política brutal de decir me desentiendo de tí y enfréntate a la adversidad de tu realidad y a ver qué puedes hacer, sino la de: entiendo cuál es la situación en la que estás viviendo $\mathrm{y}$ te voy a proporcionar medios que la sociedad pone a tu disposición a través de la educación, a través de la promoción humana, a través de la promoción económica, para que puedas salir adelante.

Insisto en que a todo este problema no tenemos que plantearlo únicamente en términos económicos. Seguramente buscar la estrategia de dar vitalidad a algunas formas de economía campesina para generar un volumen de productos agrícolas que abastecieran las necesidades del país sería la estrategia más absurda. Pero si lo vemos desde el punto de vista de qué salida darle a esos grupos humanos para los cuales no tenemos suficientes empleos industriales, suficientes puestos en la ciudad, suficientes alternativas fuera de las condiciones en las que están viviendo, es para que nos preocupemos por encontrar soluciones que ayuden a estas familias a salir adelante.

Como les decía yo al principio, acepté con muchísimo gusto la invitación a venir aquí y de traerles estos puntos de vista, simple- 
mente como reflexiones respecto a una cuestión que no se nos debe olvidar que existe y que es una parte fundamental de nuestra problemática presente. 